\title{
Significance of changes in inflammatory parameters following uterine artery embolization in pre-menopausal females
}

\author{
VASILEIOS SOUFTAS $^{1}$, DORELIA DEUTERAIOU ${ }^{2}$, XANTHOULA ANTHOULAKI $^{2}$, ANNA CHALKIDOU ${ }^{2}$, \\ ANASTASIA BOTHOU ${ }^{3}$, FOTINI GAIDATZI ${ }^{2}$, GRIGORIOS TSYPSIANIS ${ }^{4}$, GEORGIOS IATRAKIS ${ }^{5}$, \\ STEFANOS ZERVOUDIS ${ }^{4}$, DIMITRIOS SOUFTAS ${ }^{6}$, SPYRIDON MICHALOPOULOS ${ }^{2}$, THEODOSIA VOGIATZAKI ${ }^{7}$, \\ GEORGE GALAZIOS $^{2}$, NIKOLAOS NIKOLETTOS ${ }^{2}$ and PANAGIOTIS TSIKOURAS ${ }^{2}$
}

\begin{abstract}
Departments of ${ }^{1}$ Interventional Radiology and Medical Imaging and ${ }^{2}$ Obstetrics and Gynecology, Medical Faculty, Democritus University of Thrace, Alexandroupolis 68100; ${ }^{3}$ Department of Obstetrics and Mastology, Rea Hospital, Athens 17564; ${ }^{4}$ Department of Medical Statistics, Medical Faculty, Democritus University of Thrace, Alexandroupolis 68100;

${ }^{5}$ University of West Attica, Department of Midwifery, Athens 17564; Departments of ${ }^{6}$ Social Administration and

${ }^{7}$ Anesthesiology and Pain Treatment, Democritus University of Thrace, Alexandroupolis 68100, Greece
\end{abstract}

Received August 23, 2019; Accepted December 19, 2019

DOI: $10.3892 / \mathrm{etm} .2020 .8652$

\begin{abstract}
The purpose of the present study was to describe the course of changes in laboratory inflammatory markers following bilateral uterine artery embolization (UAE) as a treatment for leiomyomas and adenomyosis. The body temperature was measured and blood samples were collected to determine white blood cell (WBC) count and C-reactive protein (CRP) levels in 270 patients on the day prior to UAE and for up to 4 days post-embolization. Aside from a single case with a non-inflammatory complication, none of the other cases had any complications. Post-UAE leukocytosis with a mean maximum value of $10.8 \pm 3.5 \times 10^{9} / 1$ (range, $5.9-18.6 \times 10^{9} / 1$ ) was observed one-year post-intervention. The mean leukocyte numbers were indicated to be higher on day 3 post-UAE. The CRP level was also increased post-UAE, with a mean maximum value of $7.75 \pm 3.5 \mathrm{mg} / \mathrm{dl}$. Maximum levels were reached in 8 patients on the 2 nd and in 11 patients on the 3rd post-operative day. The maximum pain score was $\sim 5.5$ and reached its lowest level at the end of the 12th week post-intervention. The present study did not consider an association between the embolic material used or uterus size with the level of treatment success. No complications were observed post-UAE; however, a significant increase in the WBC count was observed within the first 3 days, indicating mild leukocytosis.
\end{abstract}

Correspondence to: Professor Panagiotis Tsikouras, Department of Obstetrics and Gynecology, Medical Faculty, Democritus University of Thrace, 89 Visvisi, Alexandroupolis 68100 , Greece E-mail: tsikouraspanagiotis@gmail.com

Key words: minimally invasive procedures, uterine artery embolization, interventional radiology, image-guided procedures, advanced technology

\section{Introduction}

Approximately $20-40 \%$ of females of reproductive age are diagnosed with leiomyomas, which consist of striated muscle fibers arranged in a spiral pattern separated from the natural uterine stroma by connective tissue $(1,2)$. The symptoms of leiomyomas and adenomyosis, the pathology of which includes the endometrium breaking through the myometrium, include bleeding abnormalities, mainly menorrhagia (50\%) (3). These symptoms require treatment, which may be conservative or surgical (3). Treatment is personalized and based on the symptoms, the location and size of the leiomyomas and the patient's preferences regarding preservation of fertility. Surgical resection includes total hysterectomy, open or laparoscopic myomectomy or, in cases with submucosal tumors, hysteroscopic resection (4). Alternative methods for the treatment of uterine leiomyomas include myolysis, interstitial thermotherapy and pharmaceutical hormone therapy with the administration of gonadotropin-releasing hormone agonists, aromatase inhibitors, oral contraceptives (estrogen-progestogen combination or progestogen alone) or placement of hormone-releasing intrauterine devices $(5,6)$. Anti-progestin agents, among which mifepristone is the most extensively investigated, act at the level of progesterone receptors, which are abundant in uterine leiomyomas (7).

Uterine artery embolization (UAE) has been used as an effective alternative method in the treatment of leiomyomas and adenomyosis and is performed by percutaneous puncture of a common femoral artery, selective catheterization of both uterine arteries and injection of agents, such as polyvinyl alcohol (PVA) particles or acrylic microspheres, for permanent embolization $(8,9)$. The procedure achieves vascular hypoxia followed by degeneration and size reduction of the leiomyomas or adenomyomas/adenomyosis. Pain and inflammation are the most common post-UAE complications (10). To estimate the degree of inflammation caused by UAE, the levels of the patients' inflammatory markers were recorded 
immediately after the UAE and on a weekly basis during their hospital stay and following discharge. The aim of the present study was to evaluate the course of changes in inflammatory parameters and pain post-UAE, in order to evaluate the effect of UAE on the quality of life of the patients and to determine whether UAE may be recommended as a safe alternative treatment option, as compared with hysterectomy, in pre-menopausal females with uterine leiomyomas and adenomyosis. It was hypothesized that inflammation was the major reason for the occurrence of post-interventional pain [the inflammatory parameters that were investigated were white blood cell count (WBC) and C-reactive protein (CRP)] and that WBC count and CRP levels are crucial in acute-phase reactions and in the inflammatory process triggered by UAE.

\section{Patients and methods}

Patients and pre-operative examinations. A total of 270 pre-menopausal females with a mean age of 42 years and 6 months \pm 5 years and 7 months-(range, 38-50 years) underwent UAE for uterine leiomyomas and/or adenomyosis. Patients were examined between November 2013 and December 2017. CRP and WBC count measurements were performed prior to and following UAE. All patients provided written informed consent prior to the UAE and underwent MRI, either on a 1 Tesla scanner (GE Healthcare) or on a 1.5 Tesla magnet (Philips Multiva) up to 60 days prior to the procedure. MRI included at least sagittal, coronal and axial T2-weighted images (with and without fat saturation), transverse T1-weighted images, and transverse, sagittal and coronal fat saturated T1-weighted images after contrast administration. Diffusion imaging was applied to the majority of the patients from 2014 onwards. Ethical approval for this procedure was confirmed by the ethics committee of the University Hospital in Alexandroupolis, Democritus University of Thrace (Alexandroupolis, Greece; reference no. 8/37 10/10/13).

Exclusion criteria. Post-menopausal females, patients with serious comorbidities, patients wishing to preserve their fertility, patients with known allergy to the contrast agent utilized during the procedure and patients with a suspected malignant condition were excluded from the present study.

Procedure. The relevant symptoms noted when recording the patient history included menometrorrhagia, dysmenorrhea, dyspareunia and symptoms attributed to bulky disease or pressure on pelvic organs. Two patients who had undergone fibromyectomy followed by leiomyoma recurrence were also included. In all cases, bilateral UAE was performed in one session, with percutaneous puncture of the right common femoral artery and insertion of a $4 \mathrm{~F}$ catheter into the uterine arteries. The left uterine artery was initially selectively accessed with the crossover technique and, when the catheter bypassed the arteries supplying the vagina and cervix, administration of the embolizing particles was initiated. In the same manner, catheterization and embolization of the right uterine artery was then performed. In the majority of the patients, a 2.7 or 2.8 microcatheter was used to access the uterus following selective catheterization of the uterine artery. Hydrogel-coated acrylic microspheres (Embozene ${ }^{\mathrm{TM}}$; Celonova/Boston
Scientific) sized 500 or $700 \mu \mathrm{m}$ were used as an embolic agent in cases of adenomyosis, and the same microspheres, sized 700 and $900 \mu \mathrm{m}$, were administered slowly in cases with myomas. The criterion for stopping particle administration was the fluoroscopic identification of 'almost complete stasis' in the cases of adenomyosis and 'complete stasis' in myomas.

Post-operative care and follow-up. Regarding pain management, $50 \mathrm{mg}$ pethidine was intramuscularly administered post-intervention and after $4 \mathrm{~h}$ and then every $4 \mathrm{~h}$ as required for the first $24 \mathrm{~h}$. Tramadol (50 mg) was administered every $6 \mathrm{~h}$ and non-steroidal anti-inflammatory drug tablets were administered every $12 \mathrm{~h}$ for 1 week. Pain assessment was performed based on a visual analogue scale (from 0 to 10) (10) using the numbering pain rating scale (NPRS). After 1 day, the patients were discharged from the hospital and administered broad-spectrum third-generation cephalosporin antibiotics for 2 weeks. Antibiotics were also administered during the intervention, by intravenous injection in all cases. Clinical, laboratory and imaging follow-up examinations by transvaginal ultrasonography and MRI scans were performed at 1, 3, 6 and 12 months after the procedure.

Leiomyoma size exhibited a mean reduction of $75 \%$ over a follow-up period of 1 year post-UAE compared with the size prior to treatment.

The present study included only pre-menopausal females, particularly those who had completed their family planning. However, two unplanned pregnancies were reported, both of which were terminated. There were no cases with indications for emergency hysterectomy.

Statistical analysis. Statistical analysis of the data was performed using SPSS version 19.0 (IBM, Corp.). The normality of quantitative variables was determined using a Kolmogorov-Smirnov test. Body temperature and WBC counts were expressed as mean $\pm \mathrm{SD}$, while CRP values and pain scores were expressed as median value and interquartile range (25th to 75th percentile). Within group differences of normally distributed quantitative variables (body temperature and WBC) were examined by one-way repeated measures ANOVA while post hoc analysis was performed using the paired-samples t-test, with adjusted level of significance at $\mathrm{a}=0.005$ according to Bonferroni's correction. Within-group differences of CRP values and pain scores were examined by Friedman test; post hoc analysis was performed using Wilcoxon signed ranks test, with adjusted level of significance at $\alpha=0.01$. $P<0.05$ was considered to indicate a statistically significant difference.

\section{Results}

Description of the procedure and technical details. The procedure was performed without any technical restrictions in all patients, as punctured and catheterized arteries were always visible on display when imaged using angiography (the first step for the UAE procedure) and super-selective embolization was feasible. In 265 of the 270 patients included in the present study, the post-interventional course was free of procedure-associated complications. In 4 patients, embolization resulted in necrosis and liquefaction of submucosal 
lesions. The MRI performed during the 1st month after UAE revealed dilation of the internal cervical orifice by protrusion of the necrotic element. Antibiotic coverage and therapeutic curettage were performed without any further complications. In 1 patient, undesired embolization was reported due to unattended backflow of particles or spread of particles during the removal of the embolization catheter. The clinical examination revealed a small area of skin necrosis on the right buttock 15 days after the intervention, which was successfully treated by local application of gauzes with fucidic acid of fucidin compresses with antibiotics and healed 2 weeks later. After a period of 14 months, the same patient reported a pregnancy termination due to personal wishes. Based on the laboratory results, hormonal changes were confirmed only during the early post-interventional period. No differences were observed between anti-Müllerian hormone and follicle-stimulating hormone levels at 12 months post-treatment compared with the pre-treatment levels and there were no cases of permanent amenorrhea.

Statistically significant changes in CRP, body temperature and $\mathrm{WBC}$ were observed (all $\mathrm{P}<0.001$ ). Post hoc analysis revealed that all markers exhibited a significant increase on the second post-operative day, reaching peak values on the third day (from the initial levels; and the WBC count, $17.71 \pm 2.53 \mathrm{~K} / \mu 1$, increased by $143.3 \%$ ). Subsequently, all markers returned to the initial levels on the fourth day. The levels of all three markers were significantly higher in patients compared with healthy controls at the second and third day (Figs. 1-3).

Changes in inflammatory parameters. The chronological course of alterations in the CRP levels was clearer compared with that of the WBC count. A value of $6.0 \mathrm{mg} / \mathrm{dl}$ was set as the point of reference based on recommendations from the Department of Microbiology and Biopathology of Democritus University of Thrace for non-surgical procedures. None of the patients had an increased CRP value prior to the procedure. Post-UAE, an increase in the CRP levels to $7.75 \pm 3.5 \mathrm{mg} / \mathrm{dl}$ was observed, with level alterations ranging between 8.3 and $11.9 \mathrm{mg} / \mathrm{dl}$ (Fig. 1). The patient who developed buttock skin necrosis exhibited a value increase of up to $7.75 \mathrm{mg} / \mathrm{dl}$, whilst the other 4 patients with leiomyoma necrosis exhibited an increase of $6.4 \mathrm{mg} / \mathrm{l}$. The CRP level appeared to rise mainly between post-operative days 2 and 4 , followed by normalization. The chronological course of CRP levels is depicted in Fig. 1. A normalization in CRP levels was noted within the first 4 days, after reaching a maximum level increase on post-interventional day 3 , due the time needed for the leiomyoma to be necrotized in aseptic conditions.

Regarding the association of CRP with other parameters, the maximum CRP level values are known to depend on the quantity of microsphere UAE material used (11), inferring that the embolization of the leiomyoma mass may affect the CRP value increase, no such association was observed in the present study. The same conclusion was reached when assessing the association between CRP levels and uterine size. In the current study the same quantity of embolic agent was always used, contrary to other published studies that have investigated various embolic agents (11-14). An increase in the CRP value to $6.0 \mathrm{mg} / \mathrm{dl}$ was observed, while it reached $8.0 \mathrm{mg} / \mathrm{dl}$ or higher

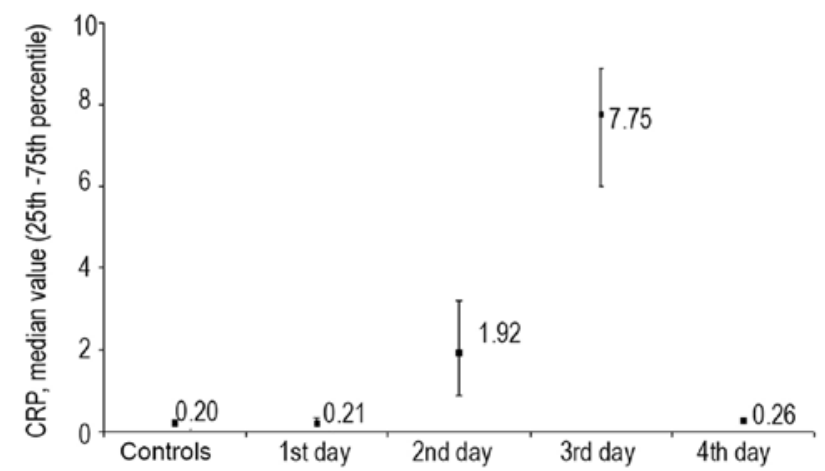

Figure 1. CRP levels, expressed as median and interquartile range (25th to 75 th percentile), in control group and women with UAE. The control group is defined as pre-UAE participants. As variability in CRP levels in the control group and on the 1st and 4th days post-UAE is small, the respective median values (25th to 75 th percentile) are provided: $0.20(0.14-0.28)$ for the control group, $0.21(0.14-0.32)$ for the 1 st day and $0.26(0.19-0.33)$ for the 4 th day. CRP, C-reactive protein; UAE, uterine artery embolization.

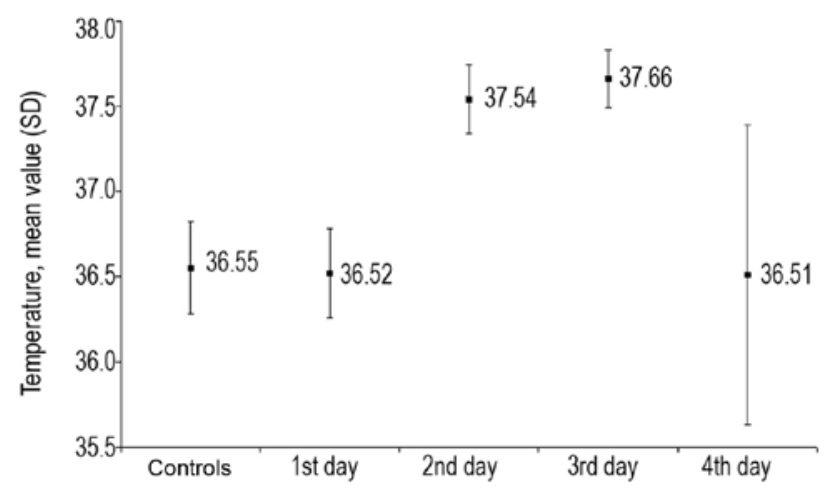

Figure 2. Mean temperature in control group and women with UAE. Values are presented as the mean \pm SD. The control is defined as pre-UAE. SD: standard deviation; UAE, uterine artery embolization. $\mathrm{P}<0.001$ vs. control.

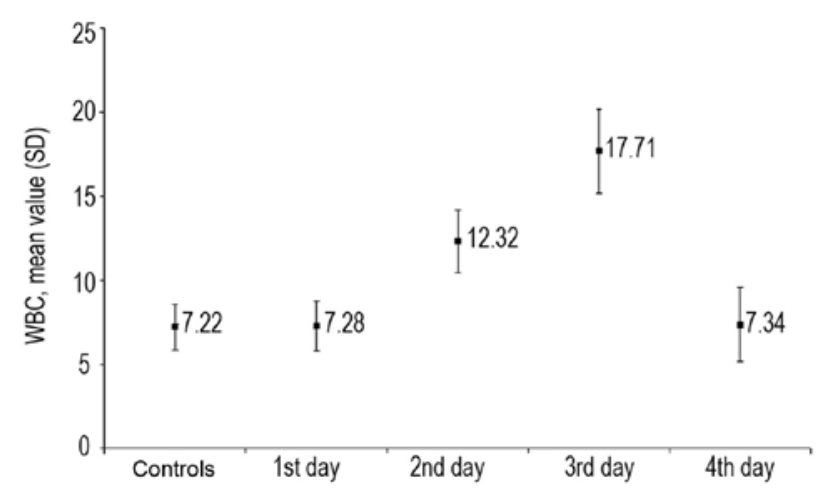

Figure 3. Mean WBC in control group and women with UAE. The control group is defined as pre-UAE participants. Values are expressed as the mean $\pm \mathrm{SD}$. The control is defined as pre-uterine artery embolization. WBC, white blood cell; SD, standard deviation. $\mathrm{P}<0.001$ vs. control.

in certain cases. These CRP changes occurred with a relative delay on post-operative days 2-4. In the majority of cases, the values subsequently returned to the normal range (Fig. 1).

Post-interventional body temperature changes are provided in Fig. 2. No cases showed an increased temperature of $>38^{\circ} \mathrm{C}$. 
Following UAE, a mild increase in the WBC count was observed with the value remaining at the upper limit of the normal range $(3.5-10.80 \mathrm{~K} / \mu \mathrm{l})$ suggested by the Department of Microbiology and Biopathology of Democritus University of Thrace).

Association between leukocytosis and time. Following UAE, an increase in the WBC count was noted from $7.22 \pm 1.75 \times 10^{9} / 1$ prior to UAE to a mean maximum WBC count of $10.8 \pm 3.5 \mathrm{~K} / \mu 1$ (range, 5.9-18.6 K/ $/ \mu$ ). In 2 patients, the WBC count appeared slightly elevated at $11 \mathrm{~K} / \mu 1$ prior to UAE (the upper limit of the normal value is $10 \mathrm{~K} / \mu \mathrm{l}$ based on reference values from the Department of Microbiology and Biopathology of Democritus University of Thrace).

Post-UAE, leukocytosis was observed in the majority of the patients on days 2 and $3(10.6 \mathrm{~K} / \mu \mathrm{l})$. An elevation was observed on day 2 , with a peak reached at day 3 , which returned to baseline levels on day 4 (Fig. 3), as well as days 8-10, with a further increase on day $11(11.5 \mathrm{~K} / \mu \mathrm{l})$ post-intervention. In patients with leiomyoma necrosis, leukocytosis of up to $15 \mathrm{~K} / \mu \mathrm{l}$ was observed (Fig. 3).

Pain score. A statistically significant reduction of post-operative pain was observed over time $\left(\chi^{2}=913.494\right.$; degrees of freedom $=11 ; \mathrm{P}<0.001)$. Post-hoc analysis using Wilcoxon's signed-ranks test, with an adjusted level of significance at $\alpha=0.01$, was then performed. At $6 \mathrm{~h}$ after UAE, the pain score ranged from 3 to 8 , with a median score of 5 (interquartile range, 4-6; mean score, $5.23 \pm 1.32$ ); it remained unchanged during the 1st post-interventional day (12th vs. 6th post-interventional hour; $\mathrm{P}=0.752)$. A significantly lower pain score was observed in the morning of the 2 nd post-interventional day $(\mathrm{P}<0.001)$, remaining at the same level throughout the day. Post-intervention the patients received an anti-pain medication (50 mg Tramadol) that was prescribed for 1-4 times per day for 4-7 days after the procedure, which positively influenced the pain course after the procedure.

The pain score exhibited a statistically significant reduction in the morning of the $3 \mathrm{rd}$ post-interventional day $(\mathrm{P}<0.001)$ and continued to decrease until the afternoon of the same day. The pain score continued to decline significantly throughout the follow-up period, reaching its lowest point at the 12th week (range, 0-3; median, 0 ; mean, $0.30 \pm 0.55$ ). The mean pain score is shown in Fig. 4.

Summary. The major results of the present study on UAE in were as follows: No significant changes in inflammatory parameters, specifically the CRP values and WBC counts; no marked fluctuation in pain levels and no life-threatening complication post-interventional UAE occurred. No case of permanent amenorrhea was encountered. The second, third and fourth measurements of the inflammatory parameters were performed at 3,6 and 12 months post-intervention.

\section{Discussion}

A number of molecular and cytogenetic studies have indicated that leiomyomas are tumors that originate from a single cell (monoclonal origin) and that multiple uterine leiomyomas in the same uterus are of completely independent origin (15-18).
Although the majority of uterine leiomyomas appear to have a normal karyotype, $\sim 40 \%$ display chromosomal abnormalities, which may be divided into 7 major cytogenetic subcategories: i) Reciprocal translocation of the 12th and 14th chromosomes [t $(12 ; 14)]$; ii) chromosome $6(6 \mathrm{p} 21)$ short-arm rearrangement; iii) deletions in the long arm of chromosome 7 [del (7) q22q32)]; iv) deletions in the long arm of chromosome 3; v) long-arm rearrangements in chromosome 10; vi) trisomy12; and vii) rearrangements in chromosome $\mathrm{X}$.

The various mutation types in leiomyomas indicate that genetic mechanisms underlie their development. A different expression profile of miRNAs has been identified in uterine leiomyomas compared with that in the normal myometrium (15-18). Leiomyomas display intense mitotic activity in the smooth muscle cell component and reduced apoptosis (programmed cell death). These two factors are considered to be a result of progesterone activity and lead to an increase in tumor size (15-18). Progesterone increases the protein expression of Bcl-2, which prevents cell apoptosis, and at the same time, it inhibits the expression of tumor necrosis factor- $\alpha$, a factor promoting apoptosis. Estrogens are considered to promote leiomyoma development by increasing the levels of the growth factors insulin-like growth factor-1, epidermal growth factor receptor, transforming growth factor (TGF)- $\beta 1$, TGF- $\beta 3$ and platelet-derived growth factor, and contribute to the abnormal survival of uterine leiomyoma cells by reducing factor $\mathrm{p} 53$, increasing anti-apoptotic factor purkinje cell protein 4 expression and antagonizing peroxisome proliferator-activated receptor- $\gamma$ signaling (15-18).

UAE is a minimally invasive procedure that aims to improve symptoms by interrupting the blood flow to leiomyomas and reduce blood flow to the muscles at the arteriolar level, using bilateral hyperselective catheterization of the myometrial feeder arteries and release of embolizing particles (particles $500-900 \mu \mathrm{m}$ in diameter, usually beads of acrylic polymers or PVA particles) to induce irreversible ischemic damage and degeneration/shrinkage of the leiomyomas (19-22). According to previous studies, the treatment success rate for menometrorrhagia is $80-100 \%$ and for pressure phenomena, it is $60-100 \%(23-26)$. In these studies a decrease in leiomyoma size of $40-70 \%$ was observed in the first 6 months, followed by $50-80 \%$ in the months that ensued $(23-26,27)$. A number of studies include uterine size in the success criteria, whilst others use the number of leiomyomas as well as uterus size to assess treatment success (23-26).

Adenomyosis may be diffuse or focal (adenomyoma), and it may be pure or, more commonly, mixed (coexistent with leiomyomas), asymmetrically affecting the uterine wall of pre-menopausal females $(12,26,28)$. The disease is common in clinical practice, manifesting with non-specific symptoms and signs, including bleeding/anemia, dysmenorrhea, dyspareunia, bulk symptoms/sensitive uterus or a combination of the above caused by leiomyomas $(12,26,28)$; therefore, it is difficult to diagnose based on the clinical criteria alone. Adenomyosis occurs predominantly in multiparous females with an incidence of $5-70 \%$. In $80 \%$ of females, adenomyosis coexists with another uterine condition: Leiomyoma (up to $53 \%$ of females with adenomyosis), pelvic endometriosis and endometrial polyps (2-20\%), endometrial hyperplasia and adenocarcinoma $(12,26,28,29)$. Approximately $35 \%$ of 


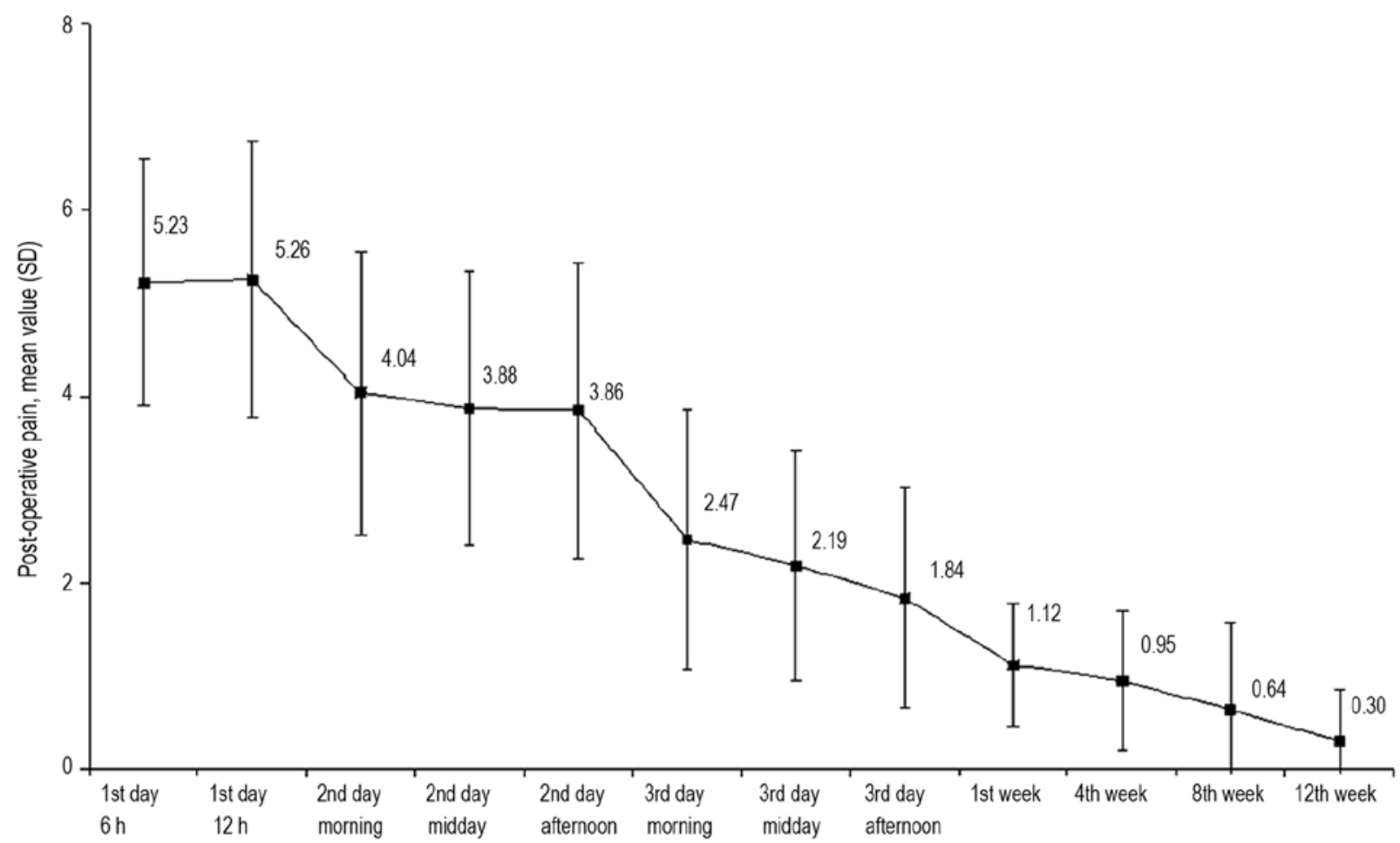

Figure 4. Mean post-interventional pain. Values are expressed as the mean \pm SD. The graph indicates that the post-interventional pain gradually decreased. $\mathrm{SD}$, standard deviation.

females with adenomyosis are asymptomatic and the diagnosis is based on routine gynecological transvaginal ultrasound; MRI contributes decisively to the diagnosis. For the differential diagnosis and staging of the disease, MRI is clearly the examination of choice due to its sensitivity (88-93\%) and specificity (66-91\%) (12,26,28-30). However, clinical diagnosis of adenomyosis is only hypothetical and the disease is definitively diagnosed based on histological examination following hysterectomy $(12,26,28-30)$.

Inflammation appears at a rate of $1-2 \%$ and is based on tissue reaction to post-interventional ischemia; inflammation is an interaction between cells and cytokines and should be diagnosed at an early stage in order to prevent sepsis, emergency hysterectomy and death $(11,13,14,31)$. The inflammatory reactions resulting from UAE intervention in combination with post-ischemic and post-necrotic reactions is the major explanation for the occurrence of pain. Serious complications may appear even at 6 months post-treatment $(11,13,14,31)$. Any alterations in inflammatory parameters, body temperature or leukocytosis, along with CRP levels and pain evaluation, should be monitored until 6 months post-embolization (11,13,14,31-36). CRP is an acute-phase pro-inflammatory cytokine, which is crucial in the acute phase of inflammation and increases progressively in association with the inflammatory process $(11,13,14,31-36)$.

In the present study, leukocytosis of up to $16.0 \mathrm{~K} / \mu 1$ and an increase in CRP levels of up to $8.0 \mathrm{mg} / \mathrm{l}$ were not considered alarming based on the recommendations of the Departments of Microbiology and Biopathology, Democritus University of Thrace, Greece. It is recommended that patients should be informed in detail in case of abdominal pain, heavy vaginal bleeding and an increased temperature, and advised to contact their doctor. To date, $\sim 100,000$ successful UAEs have been performed in total worldwide (20). In our institution, (the Department of Interventional Radiology and Medical Imaging, Democritus University of Thrace) approximately 400 embolizations have been performed. It is evident that leiomyoma embolization, similarly to laparoscopic or endoscopic myolysis, should be performed following strict criteria and parameters. A gynecologist and an interventional radiologist must confirm therapeutic indications. The frequency of complications among the participants in the present study was low. Necrosis and liquefaction of submucosal leiomyomas were reported in 4 cases and a small area of skin necrosis on the right buttock developed in 1 case; these were successfully treated either by fractional curettage or, in the latter case, by conservative local therapy. Various retrospective and prospective studies on UAE, as well as case reports on associated complications, have been published in the international literature $(37,38)$.

Complications are generally caused by either the catheterization procedure or the effects of uterine ischemia, which may cause necrosis, pain and sepsis. The ovaries may also be affected. Deaths following UAE are rare $(1: 1,600)$ and are mainly attributed to pulmonary embolism, which may be due to the effect of the necrotic tissue on activation of the coagulation cascade and on inflammation $(37,38)$.

The complications of catheterization, including hematoma, allergy to contrast media and pseudo-aneurysm or vascular separation, are rare $(<1 \%)(37,38)$. Elimination of uterine leiomyomas occurs in $5 \%$ of cases and may cause inflammation requiring a repeat uterine embolization or hysterectomy. Necrotic tissue, if not removed in a timely manner, may become infected and the condition may be severe $(37,38)$. Cases with submucosal leiomyomas should be treated hysteroscopically. 
Ischemia may lead to the development of endometritis, pelvic inflammation and pyometra, with poor outcome unless hysterectomy is performed $(37,38)$.

It has been reported that in $11 \%$ of the cases, an additional circulatory network is present between the ovaries and the uterus, while in $5 \%$ of cases the ovaries are supplied exclusively by uterine vessels (27). The rates of transient or permanent amenorrhea may vary according to the age of the patient. While among young females, the rates range from 0 to $5 \%$, they may reach $43 \%$ in females aged $>45$ years (27). It has been estimated that, if a patient experiences amenorrhea for a period of 3-11 months, menopause is likely to occur ( $95 \%)$ within the next 4 years (27). On the other hand, females who have amenorrhea for 1 year have a $10.5 \%$ chance of having a normal menstrual cycle in the future if their age is between 45-49 years (27).

The rate of post-UAE complications is markedly lower compared with that after hysterectomy, as reported in previous studies. In retrospective studies comparing myomectomy with UAE, there was a requirement for transfusion in $12 \%$ of cases and the incidence of complications was $19-25 \%$ after fibromyomectomy vs. 0 and $4.2 \%$ after UAE, respectively $(39,40)$. The duration of hospitalization and the time until patients returned to work after UAE were $\sim 1$ and 10 days, respectively, which were significantly shorter compared with those for surgical methods $(39,40)$.

The present results are consistent with those of other studies $(27,37,39,40)$ that stated that inflammatory parameters are not important prognostic factors following UAE. It is crucial to develop an objective method for assessing bleeding during menstruation in order to select the most suitable candidates to undergo effective therapeutic approaches other than invasive surgery, including UAE.

\section{Acknowledgements}

Not applicable.

\section{Funding}

No funding was received.

\section{Availability of data and materials}

The datasets used and/or analyzed during the current study are available from the corresponding author on reasonable request.

\section{Authors' contributions}

VS participated in the review process, prepared the manuscript, performed all procedures and described the techniques. DD collected data and relevant literature. XA contributed to manuscript corrections and collected data and relevant literature. AC, AB and FG collected data and literature. GT performed the statistical analysis. GI, SZ and GG corrected and modified the manuscript. DS and SM corrected the figures. TV was responsible for the pain protocol. NN contributed to study design. PT participated in the review process, prepared the manuscript and made substantive intellectual contributions to the published study. All authors read and approved the final version of the manuscript.

\section{Ethics approval and consent to participate}

Approval for this procedure was confirmed by The Ethics Committee of the University Hospital in Alexandroupolis, Democritus University of Thrace (Alexandroupolis, Greece; reference no. $8 / 37$ 10/10/13) and patients provided written informed consent to their participation in the study.

\section{Patient consent for publication}

All patients provided written informed consent to publication of their data for a scientific purpose before the procedure.

\section{Competing interests}

The authors declare that they have no competing interests.

\section{References}

1. Calaf J, Arqué M, Porta $\mathrm{O}$ and D'Angelo E: The fibroid as clinical problem. Med Clin (Barc) 141 (Suppl 1): S1-S6, 2013 (In Spanish).

2. O'Sullivan M and Overton C: Tailor management to the patient with fibroids. Practitioner 261: 19-22, 2017.

3. Donnez J and Dolmans MM: Uterine fibroid management: From the present to the future. Hum Reprod Update 22: 665-686, 2016.

4. Falcone T and Parker WH: Surgical management of leiomyomas for fertility or uterine preservation. Obstet Gynecol 121: 856-868, 2013.

5. Stovall DW: Alternatives to hysterectomy: Focus on global endometrial ablation, uterine fibroid embolization, and magnetic resonance-guided focused ultrasound. Menopause 18: 437-444, 2011.

6. Sabry M and Al-Hendy A: Medical treatment of uterine leiomyoma. Reprod Sci 19: 339-353, 2012.

7. Carbonell Esteve JL, Riverón AM, Cano M, Ortiz AI, Valle A, Texidó CS and Tomasi G: Mifepristone $2.5 \mathrm{mg}$ versus $5 \mathrm{mg}$ daily in the treatment of leiomyoma before surgery. Int J Womens Health 4: 75-84, 2012.

8. Wang S, Meng X and Dong Y: The evaluation of uterine artery embolization as a nonsurgical treatment option for adenomyosis. Int J Gynaecol Obstet 133: 202-205, 2016.

9. Tomislav S, Josip M, Liana CS, Marko V, Marko J, Ante R, Dzenis J, Leo G, Ivica S, Marijan T and Situm K: Uterine artery embolization as nonsurgical treatment of uterine myomas. ISRN Obstet Gynecol 2011: 489281, 2011.

10. Tropeano G, Amoroso S and Scambia G Non-surgical management of uterine fibroids. Hum Reprod Update 14: 259-274, 2008.

11. Stampfl S, Stampfl U, Bellemann N, Sommer CM, Thierjung H, Radeleff B, Lopez-Benitez R, Berger I, Kauffmann GW and Richter GM: Biocompatibility and recanalization characteristics of hydrogel microspheres with polyzene-F as polymer coating. Cardiovasc Intervent Radiol 31: 799-806, 2008.

12. Lohle PN, De Vries J, Klazen CA, Boekkooi PF, Vervest HA, Smeets AJ, Lampmann LE and Kroencke TJ: Uterine artery embolization for symptomatic adenomyosis with or without uterine leiomyomas with the use of calibrated tris-acryl gelatin microspheres: Midterm clinical and MR imaging follow-up. J Vasc Interv Radiol 18: 835-841, 2007.

13. Stampfl S, Bellemann N, Stampfl U, Sommer CM, Thierjung H, Lopez-Benitez R, Radeleff B, Berger I and Richter GM: Arterial distribution characteristics of Embozene particles and comparison with other spherical embolic agents in the porcine acute embolization model. J Vasc Interv Radiol 20: 1597-1607, 2009.

14. Joffre F, Tubiana JM and Pelage JP; Groupe FEMIC: FEMIC (Fibromes Embolisés aux MICrosphères calibrées): Uterine fibroid embolization using tris-acryl microspheres. A French multicenter study. Cardiovasc Intervent Radiol 27: 600-606, 2004. 
15. Gross KL and Morton CC: Genetics and the development of fibroids. Clin Obstet Gynecol 44: 335-349, 2001.

16. Meloni AM, Surti U, Contento AM, Davare J and Sandberg AA: Uterine leiomyomas: Cytogenetic and histologic profile. Obstet Gynecol 80: 209-217, 1992.

17. Ligon AH and Morton CC: Genetics of uterine leiomyomata. Genes Chromosomes Cancer 28: 235-245, 2000.

18. Marsh EE, Lin Z, Yin P, Milad M, Chakravarti D and Bulun SE: Differential expression of microRNA species in human uterine leiomyoma versus normal myometrium. Fertil Steril 89: 1771-1776, 2008

19. Raikhlin A, Baerlocher MO and Asch MR: Uterine fibroid embolization: CME update for family physicians. Can Fam Physician 53: 25025-25026, 2007.

20. Marshburn PB, Matthews ML and Hurst BS: Uterine artery embolization as a treatment option for uterine myomas. Obstet Gynecol Clin North Am 33: 125-144, 2006.

21. Szkodziak P, Szkodziak F, Trzeciak K and Czuczwar P. Minimally invasive procedures in the management of uterine fibroids. Prz Menopauzalny 16: 122-125, 2017.

22. Vilos GA, Allaire C, Laberge PY and Leyland N; SPECIAL CONTRIBUTORS: The management of uterine leiomyomas. J Obstet Gynaecol Can 37: 157-178, 2015.

23. Kubik-Huch RA, Weston M, Nougaret S, Leonhardt $H$, Thomassin-Naggara I, Horta M, Cunha TM, Maciel C, Rockall A and Forstner R: European society of urogenital radiology (ESUR) guidelines: MR imaging of leiomyomas. Eur Radiol 28 3125-3137, 2018

24. Cura M, Cura A and Bugnone A: Role of magnetic resonance imaging in patient selection for uterine artery embolization. Acta Radiol 47: 1105-1114, 2006.

25. Early HM, McGahan JP, Scoutt LM, Revzin M, Lamba R Corwin M, Fananapazir G and Sekhon S: Pitfalls of sonographic imaging of uterine leiomyoma. Ultrasound Q 32: 164-174, 2016.

26. Tamai K, Koyama T, Umeoka S, Saga T, Fujii S and Togashi K Spectrum of MR features in adenomyosis. Best Pract Res Clin Obstet Gynaecol 20: 583-602, 2006.

27. Tsikouras P, Manav B, Koukouli Z, Trypsiannis G, Galazios G, Souftas D and Souftas V: Ovarian reserve after fibroid embolization in premenopausal women. Minim Invasive Ther Allied Technol 26: 284-291, 2017.

28. Kim MD, Kim S, Kim NK, Lee MH, Ahn EH, Kim HJ, Cho JH and Cha SH: Long-term results of uterine artery embolization for symptomatic adenomyosis. AJR Am J Roentgenol 188: 176-181, 2007.

29. Levgur M: Therapeutic options for adenomyosis: A review. Arch Gynecol Obstet 276: 1-15, 2007.

30. Alvi FA, Glaser LM, Chaudhari A, Tsai S and Milad MP New paradigms in the conservative surgical and interventional management of adenomyosis. Curr Opin Obstet Gynecol 29: 240-248, 2017.
31. Stampfl S, Stampfl U, Bellemann N, Radeleff B, Lopez-Benitez R, Sommer CM, Thierjung H, Berger I and Richter GM: Immunohistochemical characterization of specific inflammatory tissue reactions following embolization with four different spherical agents in the minipig kidney model. J Vasc Interv Radiol 20: 936-945, 2009.

32. Kim HS, Czuczman GJ, Nicholson WK, Pham LD and Richman JM: Pain levels within 24 hours after UFE: A comparison of morphine and fentanyl patient-controlled analgesia. Cardiovasc Intervent Radiol 31: 1100-1107, 2008.

33. Lampmann LE, Lohle PN, Smeets A, Boekkooi PF, Vervest H, van Oirschot CM and Bremer RC: Pain management during uterine artery embolization for symptomatic uterine fibroids. Cardiovasc Intervent Radiol 30: 809-811, 2007.

34. Jensen LL, Handberg G, Helbo-Hansen HS, Skaarup I, Lohse T, Munk T and Lund N: No morphine sparing effect of ketamine added to morphine for patient-controlled intravenous analgesia after uterine artery embolization. Acta Anaesthesiol Scand 52: 479-486, 2008.

35. Roth AR, Spies JB, Walsh SM, Wood BJ, Gomez-Jorge J and Levy EB: Pain after uterine artery embolization for leiomyomata: Can its severity be predicted and does severity predict outcome? J Vasc Interv Radiol 11: 1047-1052, 2000.

36. Valdes-Devesa V, Jimenez MDM, Sanz-Rosa D, Espada Vaquero M, Alvarez Moreno E and Sainz de la Cuesta Abbad R: Preoperative diagnosis of atypical pelvic leiomyoma and sarcoma: The potential role of diffusion-weighted imaging. J Obstet Gynaecol 39: 98-104, 2019.

37. Margau R, Simons ME, Rajan DK, Hayeems EB, Sniderman KW, Tan K, Beecroft JR and Kachura JR: Outcomes after uterine artery embolization for pedunculated subserosal leiomyomas. J Vasc Interv Radiol 19: 657-661, 2008.

38. McLucas B, Chespak L and Kaminsky D: Myoma necrosis following Gelfoam embolization of uterine myomata. Minim Invasive Ther Allied Technol 17: 200-204, 2008.

39. Choi HJ, Jeon GS, Kim MD, Lee JT and Yoon JH: Is uterine artery embolization for patients with large myomas safe and effective? A retrospective comparative study in 323 patients. J Vasc Interv Radiol 24: 772-778, 2013.

40. de Bruijn AM, Lohle PN, Huirne JA, de Vries J, Twisk M; QUESTA-Trial Group and Hehenkamp WJ: Uterine artery embolization versus hysterectomy in the treatment of symptomatic adenomyosis: Protocol for the randomized QUESTA trial. JMIR Res Protoc 7: e47, 2018.

This work is licensed under a Creative Commons Attribution-NonCommercial-NoDerivatives 4.0 International (CC BY-NC-ND 4.0) License. 